RESENHAS

\title{
HISTÓRIA DO MOVIMENTO LGBT NO BRASIL
}

\author{
Kamila Teischmann ${ }^{1}$
}

GREEN, James; QUINALHA, Renan; CAETANO, Márcio; FERNANDES, Marisa; (org.). História do Movimento LGBT no Brasil. 1. ed. São Paulo: Alameda, 2018.

A dinâmica política e social do Brasil nos últimos anos, desde o malfadado e arbitrário impeachment da Presidenta Dilma Rousseff em 2016, tem exigido atos e movimentos de resistência quanto a questões alusivas aos direitos de populações historicamente excluídas e marginalizadas, de modo que a celebração em forma de obra literária englobando variados recortes existenciais representa, também, uma simbólica forma de existir e resistir em meio ao caos que o presente impõe.

O livro em questão é organizado por 04 (quatro) pesquisadores, professores e expoentes no estudo e disseminação de conhecimento acerca das múltiplas identidades, diversidade e culturas no Brasil. São eles: James N. Green, Márcio Caetano, Marina Fernandes e Renan Quinalha.

Nesse livro, escreveram ou colaboraram redigindo 04 (quatro) textos, e dignaram-se em organizar outros 26 (vinte e seis) escritos, totalizando nesta obra a reunião de 30 (trinta) trabalhados de 35 (trinta e cinco) autoras lautores.

Não me permitirei discorrer sobre cada um dos organizadores ou de cada um dos autores, seja pela possibilidade de cometer injustiças, tamanha a importância dessas pessoas, seja pela quantidade de protagonistas desse feito, de modo a impedir a coexistência com uma pretendida resenha a se construir.

A obra não possui capítulos ou separações numérico-cronológica sobre os assuntos, fatos e opiniões destacadas, o que, em certa medida, se afina ao próprio título

\footnotetext{
${ }^{1}$ Mestranda em Política pela Universidade Federal de Mato Grosso - UFMT. Advogada. Vice-presidente da Comissão da Diversidade Sexual da OAB-MT.E-mail: kamilamichiko@gmail.com
}

Vol. 03, N. 12, Out. - Dez., 2020 - http://periodicoscientificos.ufmt.br/ojs/index.php/rebeh/index 
do livro e do movimento LGBT, rompendo padrões, fugindo a uma normatização, contagem e controle. Os textos são reunidos e passam, um a um, a descrever momentos e experiências próprias ou de atrizes \atores que são parte da história do movimento.

O marco adotado pelos organizadores foi o ano de 1978, celebrando, assim, no ano da publicação da obra (2018), de 40 (quarenta) anos da História do Movimento LGBT no Brasil. Naquele ano, conforme se indica na apresentação do livro, ganhou força o Movimento Homossexual Brasileiro (MHB).

Em vista do ano destacado do surgimento do MHB no Brasil, nota-se seu florescer em plena ditadura militar e, nesse sentido, não são poucas as referências a esse período que, catalisando um sentimento reacionário difuso em um discurso coeso, associou a homossexualidade a uma forma de degeneração e de corrupção da juventude, referindo a uma ditadura hétero-militar, dada a uma política sexual oficializada e institucionalizada no período (QUINHALHA, 2018).

Submersos na realidade ditatorial da época, embora com especificidades locais em cada parte do país, infere-se uma conduta opressiva socialmente e repressiva institucionalmente quanto as ações policiais, que passam a se instrumentalizar como verdadeiras medidas de higienização.

Nesse sentido, a Cidade de São Paulo, sempre um grande centro de acontecimentos, recebe atenção destacada. Em um rico levantamento de fatos e notícias da época, revela uma política higienista, tendo por líder o Delegado José Wilson Richetti, que perpetrou incontáveis violações à existência e dignidade das pessoas LGBT, notadamente as mulheres travestis em operações como a denominada "Operação Limpeza" em locais sabidamente frequentados por essas pessoas. Em 1980 a aludida operação prendeu mais de 700 (setecentas) pessoas, em sua maioria prostitutas, travestis e homossexuais para as chamadas averiguações.

Também originária das ações de Richetti, o que ficou conhecimento como uma Stonewall Brasileira decorre da "Operação Sapatão” no Ferro's Bar, que buscava deter frequentadoras do estabelecimento, ensejando na revolta por parte dessas e daqueles que presenciaram o ocorrido, tendo a truculência de Richetti realmente marcado uma era de arbitrariedades (OCANHA, 2018). 


\section{REBE员}

No mesmo contexto das décadas de 70 e 80 , retrata-se o surgimento de periódicos como o pioneiro "Lampião de Esquina", com todas as dificuldades de se expressar em jornais de considerável alcance temas afetos ao gênero e à sexualidade, chegando até mesmo seus editores a sofrerem perseguição, diante da instauração de inquérito policial sob a acusação de violar a legislação da imprensa e de ir contra a famosa dupla "moral" e "bons costumes" que até hoje nos ronda (MacRAE, 2018).

Vários grupos passam a ser organizar nos eixos Rio-São Paulo, mas também na região Norte e Nordeste, com destaque para a Cidade de Salvador-BA e Manaus-AM, sendo rememorados na obra até mesmo individualmente, em capítulos específicos, com recortes e experiências únicas retratadas que chegam mesmo a emocionar tamanha a sensibilidade expressa e traduzida em personagens marcantes em algumas passagens.

Entre a passagem da ditadura militar para a redemocratização, a obra rememora as agruras sofridas advindas do duro golpe da epidemia de HIV-AIDS que, ao mesmo tempo em que representou um retrocesso no sentido de reconhecimento de dignidade às pessoas LGBTs, que passaram a ser alvo de preconceito ainda mais acentuado, notadamente de alas neopentecostais que denominaram a epidemia de "peste gay", também houve uma espécie de reunificação e verbalização às claras de questões atinentes à sexualidade, e, de alguma forma, discuti-la representando um progresso nesse sentido (CAETANO, NASCIMENTO, RODRIGUES, 2018).

Emergindo para a redemocratização, o Brasil de reabertura é descrito com a consolidação dos movimentos iniciados no sofrido período ditatorial e avanços no campo político-institucional.

Nesse contexto, a movimentação de grupos sociais foi crucial para que o Conselho Federal de Medicina (CFM) exclui-se o Código 302.0 da Classificação Internacional de Doenças, da Organização Mundial da Saúde, cujo capítulo V dizia "Transtornos Mentais" e qualificava a homossexualidade como "desvio e transtorno sexual". Essa conquista foi especialmente liderada pelo Grupo Gray da Bahia (BBG) que até os dias atuais segue com um indispensável trabalho de luta e resistência (CÂMARA, 2018). 
De meados para o fim dos anos 80 registra-se a mobilização unificada de grupos organizados buscando estabelecer na Constituinte de 1988 um marco na consolidação de lutas por direitos. Entretanto, muito embora a chamada Carta Cidadã tenha de fato previsto avanços no sentido de reconhecimento de direitos e liberdades individuais, não logrou êxito a tentativa de se prever expressamente a proibição e discriminação por orientação sexual e de gênero. Entretanto, nesse período o MHB se aproximou e influenciou no que se refere a atuação dos partidos políticos para obter avanços e construir acessos no parlamento no que tange a questão LGBT.

Nessa toada, nos inícios dos anos 90 a tentativa de inclusão da "expressão proibição de discriminação por orientação sexual" foi retomada na Revisão Constitucional e novamente rejeitada, com posteriores projetos de Emenda Constitucional, arquivados (CÂMARA, 2018).

Ainda anos 90 surge o que se pode considerar como o acontecimento mais próximo de se considerar a primeira "Parada", em 28.06.1996 na Praça Roosevelt em São Paulo-SP, havendo a necessária intervenção para se registrar sobre o formato original e encantador das paradas LGBTs no Brasil, tratando sobre seu surgimento, essência e grandiosidade, configurando-se em um ato político.

A institucionalização do movimento LGBT, aliás, é emergente e perpassa os anos 90 e meados dos anos 2000, notadamente com a eleição de Luiz Inácio Lula da Silva em 2003, havendo uma reconfiguração e mais aproximação com o Estado, observandose trânsito intenso e deslocamento de ativistas na estrutura do Estado como gestores de uma novíssima política pública LGBT (FEITOSA, 2018).

E essa nova interlocução também ganha corpo com o cyberativismo, dado ao caráter geracional dos novos participantes do movimento, destacando-se da importância desse uso especialmente para o (re)conhecimento das pessoas LGBTs a partir de relatos de outras nas redes sociais, que passa a ser, em certa medida, campo seguro para a expressão de sexualidade e identidades.

De outro lado, mesmo diante de importantes conquistas a partir dos anos 2000 com a eleição de um partido político de esquerda para o comandar o país, em um cenário mais contemporâneo e em uma arena de disputas entre os anos de 2010 e 2014, há a 


\section{REBE员}

análise da relação entre o Estado e a sociedade civil, um com o outro ou com si mesmo, bastante realista acerca dos momentos de avanços e retrocessos político-sociais, chamando à reflexão e autocrítica acerca da articulação (ou da não articulação) que resultaram no recrudescimento que ora se assiste (IRINEU, 2018).

Mesmo diante de tantos acontecimentos e até mesmo imersão do movimento no cenário político-social de maneira mais acentuada, ainda não foi suficiente para a transformação de direitos em leis, havendo com o Poder Judiciário uma relação imbricada em decorrência da omissão propositada de outros poderes, destacando-se na obra a mobilização judicial pelos direitos da diversidade sexual e de gênero no Brasil, com o reconhecimento da união estável, casamento civil, identidade de gênero e, entre a publicação da obra e este momento, advieram outras conquistas como a doação de sangue por homens homossexuais, a criminalização da homotransfobia e a educação não discriminatória nas escolas.

Não obstante, a obra revela carência na abordagem sobre as pessoas interessexuais, assexuais e não-binárias, público ainda pouco contemplado e muito hostilizado, dada a incompreensão advinda da ignorância, de modo geral, o que poderia ter agregado ainda mais à obra, dando voz e luz às vivências e fortalecendo a construção coletiva das identidades que vêm sendo ao longo da história ignoradas ou apagadas.

Em um momento de exasperação de radicalidades e conservadorismo liderado pelo atual chefe do Executivo nacional, acentuando-se o controle sobre o gênero e as sexualidades, revisitando a história e expondo parte da população, como a retratada na obra, a vulnerabilidades, dificulta-se a dimensão coletiva de construção de políticas públicas para a superação deste cenário.

O governo (Federal) atual se coloca com o propósito de promover uma contrarrevolução de políticas de direitos humanos e de igualdade e, ao contrário do que se poderia esperar do papel do Estado enquanto ente viabilizador de direitos e garantias, traz obstáculos ao exercício pleno da cidadania para a parcela da população que não considera como cidadãos.

Nesse sentido, o livro se constitui em relevante objeto para o estudo e percepção sobre o movimento e comunidade LGBT, para que se possa compreender o passado e, 
especialmente, transformar o futuro, o que já se constituiu como um grande alento diante do cenário sombrio trazido pelo avanço do neoconservadorismo.

\section{Referências}

GREEN, James; QUINALHA, Renan; CAETANO, Márcio; FERNANDES, Marisa; (org.). História do Movimento LGBT no Brasil. 1. ed. São Paulo: Alameda, 2018.

CAETANO, Marcio. NASCIMENTO, Cláudio. RODRIGUES, Alexsandro. Do caos reemerge a força: AIDS e mobilização LGBT. GREEN, James; QUINALHA, Renan; CAETANO, Márcio; FERNANDES, Marisa; (org.). História do Movimento LGBT no Brasil. 1. ed. São Paulo: Alameda, 2018.

CÂMARA, Cristina. Pecado, doença e direitos: a atualidade da agenda política do grupo Triângulo Rosa. GREEN, James; QUINALHA, Renan; CAETANO, Márcio; FERNANDES, Marisa; (org.). História do Movimento LGBT no Brasil. 1. ed. São Paulo: Alameda, 2018.

FEITOSA, Cleyton. A participação social nos 40 anos do Movimento LGBT brasileiro. GREEN, James; QUINALHA, Renan; CAETANO, Márcio; FERNANDES, Marisa; (org.). História do Movimento LGBT no Brasil. 1. ed. São Paulo: Alameda, 2018.

IRINEU, Bruna Andrade. Negociações, disputas e tensões na arena LGBT brasileira entre os anos 2010 a 2014. GREEN, James; QUINALHA, Renan; CAETANO, Márcio; FERNANDES, Marisa; (org.). História do Movimento LGBT no Brasil. 1. ed. São Paulo: Alameda, 2018.

MACRAE, Edward. Identidades homossexuais e movimentos sociais urbanos no Brasil da "Abertura". GREEN, James; QUINALHA, Renan; CAETANO, Márcio; FERNANDES, Marisa; (org.). História do Movimento LGBT no Brasil. 1. ed. São Paulo: Alameda, 2018.

OCANHA, Rafael Freitas. Repressão policial aos LGBTs em São Paulo na ditura civilmilitar e a resistência dos movimentos articulados. GREEN, James; QUINALHA, Renan; 


\section{贯BE年}

CAETANO, Márcio; FERNANDES, Marisa; (org.). História do Movimento LGBT no Brasil. 1. ed. São Paulo: Alameda, 2018.

QUINHALHA, Renan. Uma ditadura hetero-militar: notas sobre a política sexual do regime autoritário brasileiro. GREEN, James; QUINALHA, Renan; CAETANO, Márcio; FERNANDES, Marisa; (org.). História do Movimento LGBT no Brasil. 1. ed. São Paulo: Alameda, 2018.

Recebido: 20/12/2020

Aceito: 10/01/2021 